NASA Technical Memorandum 88870

(NASA-TM-888/0) NDE RELIAEILITY AND PROCESS

CCNTROL FOE SIRECTORAI CEFAYICS (NASA) $17 \mathrm{p}$

N87-12910

CSCL 140

Unclas

$\mathrm{G} 3 / 38$

44727

\title{
NDE Reliability and Process Control for Structural Ceramics
}

George Y. Baaklini

Lewis Research Center

Cleveland, Ohio

Prepared for the

32nd International Gas Turbine Conference and Exhibition sponsored by the American Society of Mechanical Engineers Anaheim, California, May 31-June 4, 1987

\section{NMSA}


NDE RELIABILITY AND PROCESS CONTROL FOR STRUCTURAL CERAMICS

\author{
George Y. Baaklini \\ National Aeronautics and Space Administration \\ Lewts Research Center \\ Cleveland, Ohio 44135
}

\title{
ABSTRACT
}

The reliability of microfocus $x$-radiography and scanning laser acoustic microscopy for detecting microvoids in silicon nitride and silicon carbide was statisticaliy evaluated. Materials- and process-related parameters that influenced the statistical findings in research samples are discussed. The use of conventional $x$-radiography in controlling and optimizing the processing and sintering of an $\mathrm{Si}_{3} \mathrm{~N}_{4}-\mathrm{SiO}_{2}-\mathrm{Y}_{2} \mathrm{O}_{3}$ composition designated NASA $6 \mathrm{Y}$ is described. Radiographic evaluation and guidance helped develop uniform high-density $\mathrm{Si}_{3} \mathrm{~N}_{4}$ modulus-of-rupture bars with improved four-point flexural strength $\left(857,544\right.$, and $462 \mathrm{MPa}$ at room temperature, $1200^{\circ} \mathrm{C}$, and $1370^{\circ} \mathrm{C}$, respectively) and reduced strength scatter.

\section{INTRODUCTION}

Advanced nondestructive evaluation (NDE) techniques to reliably detect critical flaws are needed if fracture mechanics principles are to be applied effectively in the design of ceramic heat engine components $(1,2)$. These techniques are also needed to monitor and control the fabrication process in the materials development program to make stronger and more reliable ceramics (2). Reliable ceramics requtre fabrication process control to reduce the incidence of various flaws and to ensure that any flaws that occur are noncritical. The dominant critical flaw type in monolithic ceramics is a pore $(3,4,5)$, which can cause wide strength variations and unacceptably low strength. Recent studies at the NASA Lewis Research Center $(6,7)$ have estabilshed the rellabllity of microfocus $x$-radlography and scanning laser acoustic microscopy for detecting seeded internal votds in $\mathrm{Si}_{3} \mathrm{~N}_{4}$ and $\mathrm{SiC}$ test specimens. Preliminary radiographic characterization of sintered $\mathrm{Si}_{3} \mathrm{~N}_{4}$ specimens (2) revealed the presence of large density gradients (a high-density case with a low-density core structure), which were believed to be detrimental to strength properties. Therefore a program was undertaken at NASA Lewis (3) to incorporate conventional $x$-radiographic techniques in an extensive investigation of one $\mathrm{Si}_{3} \mathrm{~N}_{4}-\mathrm{SiO}_{2}-\mathrm{Y}_{2} \mathrm{O}_{3}$ composition in order to monitor its fabrication process.

This paper describes the materials- and process-related factors that affected the reliablitty of microfocus $x$-radiography and scanning laser acoustic microscopy for detecting internal voids in $\mathrm{St}_{3} \mathrm{~N}_{4}$ and $\mathrm{SiC}$. The capability of the conventional $x$-radiographic technique in guiding powder processing and sintering parameter changes to improve the absolute density of sintered $\mathrm{Si}_{3} \mathrm{~N}_{4}$ and to eliminate detrimental density variations is emphasized. Improvements in flexural strengths and reductions in strength scatter are also described. 
MATERIALS AND PROCEDURES

The preparation of $\mathrm{SiC}$ and $\mathrm{Si}_{3} \mathrm{~N}_{4}$ specimens needed for the NDE reliability determinations is shown in $\mathrm{Fig}$. 1. The $\mathrm{Si}_{3} \mathrm{~N}_{4}$ powder had the $\mathrm{Si}_{3} \mathrm{~N}_{4}-\mathrm{SiO}_{2}-\mathrm{Y}_{2} \mathrm{O}_{3}$ composition. The SIC powder contained sintering aids and binder materials of boron and carbonaceous resins. Styrene divinyl benzene microspheres of various sizes $(50,80,115,220$, and $528 \mathrm{\mu m}$ diam) were seeded in green specimens and later burned out to create volds within the green and sintered specimens. The seeded test bars had the same densities, compositions, and shapes as typical modulus-of-rupture (MOR) bars of the same materials. Detalls on specimen fabrication, vold characterization, dimension of specimens and voids, and density determination are given in Ref. 6. Microfocus radiography (Fig. 2) and scanning laser acoustic microscopy (Fig. 3) were used to detect the seeded voids (20 to $477 \mathrm{\mu m}$ in diam) in the fabricated ceramic samples. References 6 and 7 describe in detall the radiography and SLAM systems, respectively.

The powder-processing steps of the NASA $6 \mathrm{Y} \mathrm{Si}{ }_{3} \mathrm{~N}_{4}$ composition, containing 6 wt $\mathrm{x}$ each of $\mathrm{Y}_{2} \mathrm{O}_{3}$ and $\mathrm{SiO}_{2}$, are shown in $\mathrm{Fig}$. 4. Powders were milled (grinding time, $t_{g}, 24,100$, or $300 \mathrm{hr}$ ), die pressed into bars at $21 \mathrm{MPa}$, and then isopressed at $414 \mathrm{MPa}$. A total of 690 bars (23 batches) were sintered 15 at a time at $2140^{\circ} \mathrm{C}$ in a tungsten cup. High-purity BN disks separated the bars from one another and from contact with the tungsten cup. Sintering times $t_{s}$ were $1,1.25,1.5$, and $2 \mathrm{hr}$. Nitrogen overpressures $P_{N}$ of 2.5 , 3.5, and 5.0 MPa were employed. All batches were radiographically evaluated at all stages of fabrication as described in Fig. 5. Test bars were radiographed (Fig. 6) in two modes: (1) the (W,L) mode, where $x$-rays are transmitted through the thickness of the bar, and $(2)$ the $(T, L)$ mode, where $x$-rays are transmitted through the width of the bar. Radlographic feedback on the density uniformity of the bars was used to adjust the powder-processing and sintering parameters. Four-point flexural strength tests were conducted in air at room and elevated temperatures $\left(1200\right.$ and $\left.1370^{\circ} \mathrm{C}\right)$ with inner and outer spans of 9.53 and $19.05 \mathrm{~mm}$, respectively. Strength data and radiographic density data were used to further modify the processing and sintering variables.

\section{NDE RELIABILITY}

Reliability assessment of microfocus $x$-radiography and scanning laser acoustic microscopy is probabilistic because of the combined uncertainties associated with the equipment, the operator, the flaw characteristics, etc. Therefore a statistical approach must be used to determine the detection reliability. This examination of the seeded specimens was based on either detecting or not detecting known existing voids. Since only two outcomes from this examination were possible, the probability of detection (POD) can be described by a binomial distribution. Detection data were grouped into size intervals and further rearranged by the optimized probability method ( 8 ) to calculate the POD values at the 0.95 confidence level.

Microfocus X-Radiography

NDE reliability data are presented in Figs. 7 and 8 in the form of plots of POD versus void size, expressed as a percent of total specimen thickness. 
For green materials the POO curves in Fig. $7(a)$ indicate that the detectioñ sensitivity of internal voids in sic was about the same as in sizint (1.e., 2.5 percent of thickness at a POD of 0.9 ). However, surface volds were easier to detect than internal voids in both materials (Figs. $7(b)$ and (c)). This was due to the internal voids being partially filled with powder, which reduced the contrast on the $x$-ray film. Even though internal voids of this type would simulate an interconnected porosity structure in simflar materials, it is difficult to establish reliability statistics for naturally occurring internal voids. Hence only the POD data for surface volds presented herein would apply to naturally occurring internal voids in green dry-pressed, injection-molded, or slip-cast materials. For sintered materials (Fig. 8) the detection sensitivity was about 1.5 percent of thickness for surface and internal voids in SiC, 1.5 percent of thickness for surface volds in $\mathrm{Si}_{3} \mathrm{~N}_{4}$, and better than 1.5 percent of thickness for internal volds in $\mathrm{Si}_{3} \mathrm{~N}_{4}$ at a POD of 0.9 . This high sensitivity to internal voids in sintered $\mathrm{Si}_{3} \mathrm{~N}_{4}$ was due to void morphologies that enhanced the $x$-ray attenuation depending on the density, chemical composition, and thickness of the shell surrounding the voids. Thus the image contrast of some volds was improved. A dense she 11 formation could occur for materials where high-atomic-number additives are used to promote the sintering process. When local chemical or density variations are not present, as is the case in sintered S1C, the detection reliability for internal voids can be inferred from the POD curves for surface voids (Fig. $8(b)$ ).

\section{Scanning Laser Acoustic Microscopy}

Figure 9 shows how specimen thickness and surface condition affected the POD (at 0.95 confidence level) of surface-connected volds in sintered $\mathrm{Si}_{3} \mathrm{~N}_{4}$ (9). For as-fired 2-, 3-, and 4-mm-thick specimens (with surface roughness of $8 \mathrm{um}$, peak to valley, the 0.9 POD was not attained. After the same specimens were polished to a surface roughnes 5 of $2 \mu \mathrm{m}, 0.9$ POD was achleved for all thicknesses. This acoustical opacity of the as-fired specimens was attributed to the surface roughness. However, near-surface pore distribution might have scattered the sound wave and resulted in poor void detectability. Figure 10 shows how vold size, void depth below the laser-scanned surface, and matrix material affected the POD of internal voids in sintered specimens having diamond ground surfaces (7). The boundaries of the bar graphs indicate the smallest void sizes and the maximum depths at which 0.9 POD (0.95 confidence level) was achieved. The detection sensitivity was greater for $\mathrm{Si}_{3} \mathrm{~N}_{4}$ than it was for SiC. This can be attributed to the coarser grain structure and greater porosity of SiC. These microstructural differences might have increased the ultrasonic scatter and resulted in more ultrasonic attenuation in SiC.

\section{NOE PROCESS CONTROL}

Processing and sintering conditions were modified on the basis of feedback from radiography to obtain the uniform high-density MOR bars associated with improved strength and reduced strength scatter. Figure 11 shows how these modified procedures affected the flexural strength of $\mathrm{NASA}_{6 \mathrm{Y} \mathrm{Si}} \mathrm{S}_{4}$ sintered at $2140{ }^{\circ} \mathrm{C}$. The sensitivity of radiography to the within-bar porosity distribution in the baseline and improved materials is shown in Fig. 12 . Efforts were made to eliminate the case-core structure (Figs. 6 and 12) and thereby strengthen the material and reduce its strength scatter. 
The case-core structure was examined as a function of the powder fineness and the sintering variables grinding time, sinter cup height, nitrogen overpressure, and degree of $B N$ setter contact. Radiography showed that increasing the powder fineness (by using 100- and 300-hr milling times) resulted in thinner and less distinct cases and thus improved both sinterability and uniformity. Minimizing the BN setter contact resulted in more uniform densification as a consequence of more uniform heating. But increasing nitrogen overpressure from 2.5 to 3.5 to $5.0 \mathrm{MPa}$ had no effect on the case-core structure. When using 100-hr milling time, smaller BN disks, and a nitrogen overpressure of $5.0 \mathrm{MPa}$, increasing the sintering time from 1 to $2 \mathrm{hr}$ and raising the sinter cup into a more uniform temperature zone were very effective in greatly reducing density gradients in sintered bars. The most uniform material, batch 31 (Fig. 12), was the result of the cumulative positive effects of increasing the powder grinding time from 24 to $300 \mathrm{hr}$, increasing the sintering time from 1 to $2 \mathrm{hr}$, minimizing the BN setter contact, adjusting the sinter cup height, and using powder wet-sieving procedures. Wet sieving was used to eliminate agglomerates and to reduce the size of impurity particles in green-pressed bars that vaporize during sintering and leave voids in the sintered bars.

Microstructures for the baseline batch and the optimized batch (31) were compared and related to position in the bar by reference to radiographs (Fig. 12). The top and bottom surfaces (W,L) planes of batch 31 had essentially pore-free zones of equal thickness. However, the $(W, L)$ planes of the baseline batch contained zones of dissimilar thickness and appearance and had fine porosity. The internal porosity of batch $31\left(3.24 \mathrm{~g} / \mathrm{cm}^{3}\right)$ was considerably less than that of the baseline batch $\left(3.12 \mathrm{~g} / \mathrm{cm}^{3}\right)$.

The individual and combined effects of powder fineness and each of the sintering variables on the flexural strength of NASA $6 Y$ at room temperature, $1200{ }^{\circ} \mathrm{C}$, and $1370^{\circ} \mathrm{C}$ are explained in detall in reference 3 . Only the cumulative positive effects of all the variables on flexural strength are shown in Fig. 11. In processing from batch to batch (baseline to 28 to 29 to 31 ) the room-temperature strength continually increased, with an overall improvement of 56 percent and more than a threefold reduction in the standard deviation. Strength improved 38 and 21 percent at 1200 and $1370{ }^{\circ} \mathrm{C}$, respectively. All successive improvements in the mechanical properties of sintered $\mathrm{Si}_{3} \mathrm{~N}_{4}$ were guided by $x$-radiographic characterization. For the most improved material the previously dominant fallure-causing voids were replaced by large columnar grains, which are less detrimental to strength properties.

\section{CONCLUSIONS}

The reliability of microfocus x-radiography for nondestructively evaluating sintered ceramics was affected by the seeded void morphologies, which enhanced the $x$-ray attenuation depending on the density, chemical composition, and thickness of the shell surrounding the voids. The reliability of scanning laser acoustic microscopy was affected by the specimen surface roughness and microstructural characteristics. Rough surfaces, large grains, and high porosity reduced the detection capability. 
The successful use of conventional $x$-radlography in guiding the fabri-

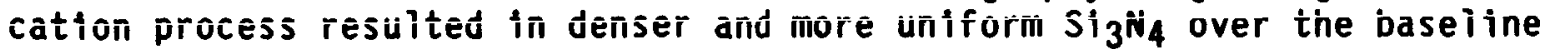
material. The improved material reached four-point average flexural strength/ standard deviation values of $857 / 36,544 / 33$, and $462 / 59 \mathrm{MPa}$ at room temperature, $1200{ }^{\circ} \mathrm{C}$, and $1370{ }^{\circ} \mathrm{C}$, respectively. These strengths represented improvements of 56,38 , and 21 percent over the baseline properties at the three test temperatures. Further, previously dominant fallure-causing voids were replaced by large grains, which are less detrimental to strength properties.

\section{REFERENCES}

1. Evans, A.G., et a1., "Failure Prediction in Structural Ceramics," Materlals Evaluation, Vol. 35, No. 4, Apr. 1977, pp. 85-96.

2. Klima, S.J., "NDE of Advanced Ceramics," Materials Evaluation, Vo1. 44, No. 5, Apr. 1986, pp. 571-576.

3. Sanders, W.A. and Baaklini, G.Y., "Correlation of Processing and Sintering Variables with the Strength and Radiography of Silicon Nitride," NASA TM-87251, 1986.

4. Nishida, K., "Silicon Nitride," The Development of Structural Fine Ceramics in Japan. The Japan Industrial and Technological Bulletin, Japan External Trade Organization, Tokyo, 1983, pp. 21-24.

5. Rice, W.R., et al., "Fractography of $\mathrm{Si}_{3} \mathrm{~N}_{4}$ and $\mathrm{SiC}$, Ceramics for High Performance Applications II, Burke, et al., eds., Brook Hill Publishing Co., Chestnut H111, MA, 1977, pp. 669-687.

6. Baaklint, G.Y. and Roth, D.J., "Probability of Detection of Internal Voids in Structural Ceramics Using Microfocus Radiography," Journal of Materials Research, Vol. 1, No. 3, May-June 1986, pp. 457-467.

7. Roth, D.J. and Baaklini, G.Y., "Rellability of Scanning Laser Acoustic Microscopy for Detecting Internal Voids in Structural Ceramics, "Advanced Ceramic Materials, Vol. 1, No. 3, July 1986, pp. 252-258.

8. Packman, P.F., et a1., "Rellability of Flaw Detection by Nondestructive Inspection," Metals Handbook, Vol. 11, 8th ed., American Society for Metals, Metals Park, OH, 1976, pp. 414-424.

9. Roth, D.J., et al., "Rellabllity of Void Detection in Structural Ceramics by Use of Scanning Laser Acoustic Microscopy," Materials Evaluation, Vo1. 44, No. 6, May 1986, pp. 761-769. 


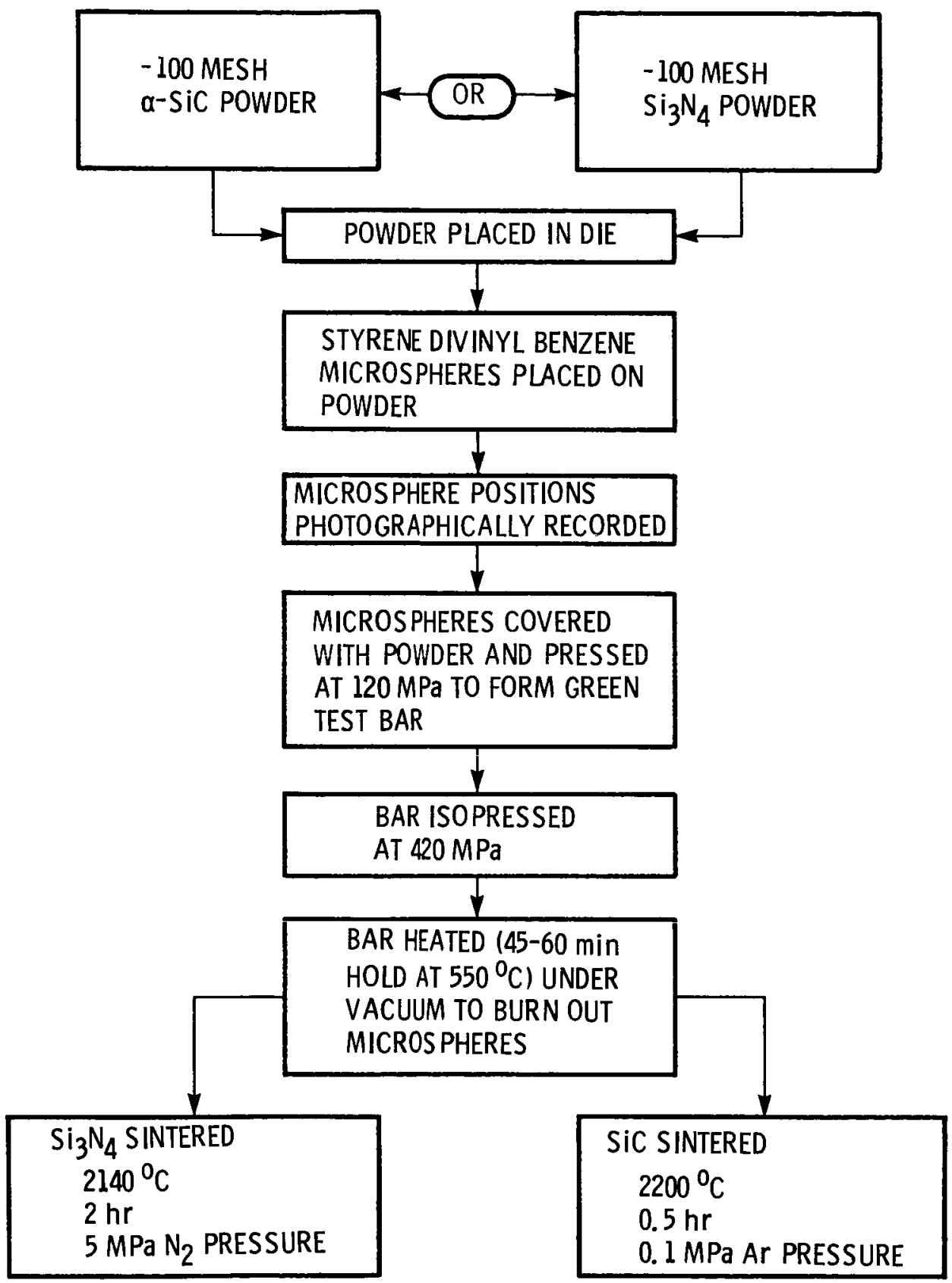

Figure 1. - Fabrication of silicon nitride and silicon carbide test specimens with seeded internal voids. 


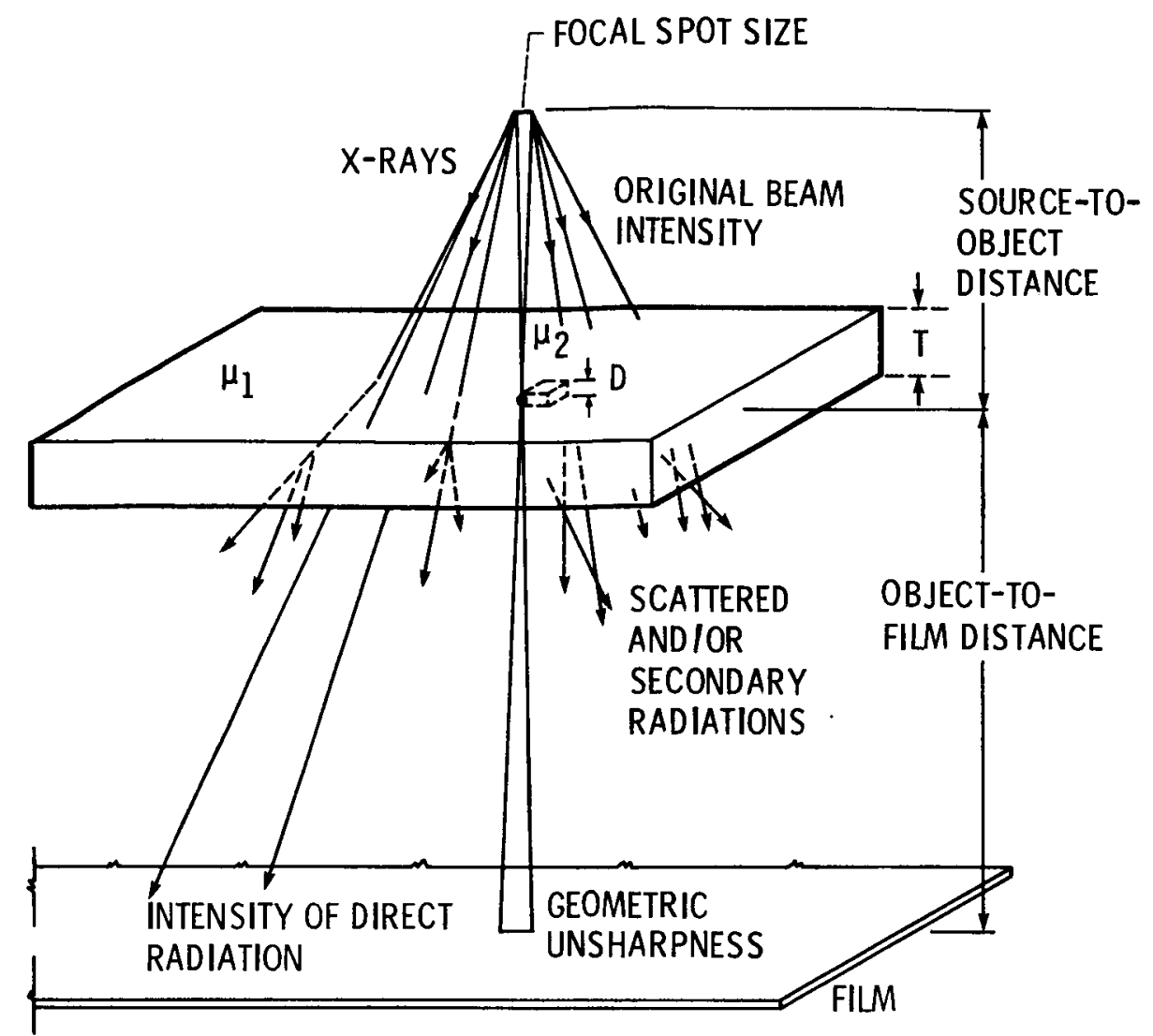

Figure 2 - Schematic configuration of microfocus projection radiography, where $D$ is thickness of defect, $T$ is thickness of sample, $\mu_{1}$ is attenuation coefficient of matrix, and $\mu_{2}$ is attenuation coefficient of defect.

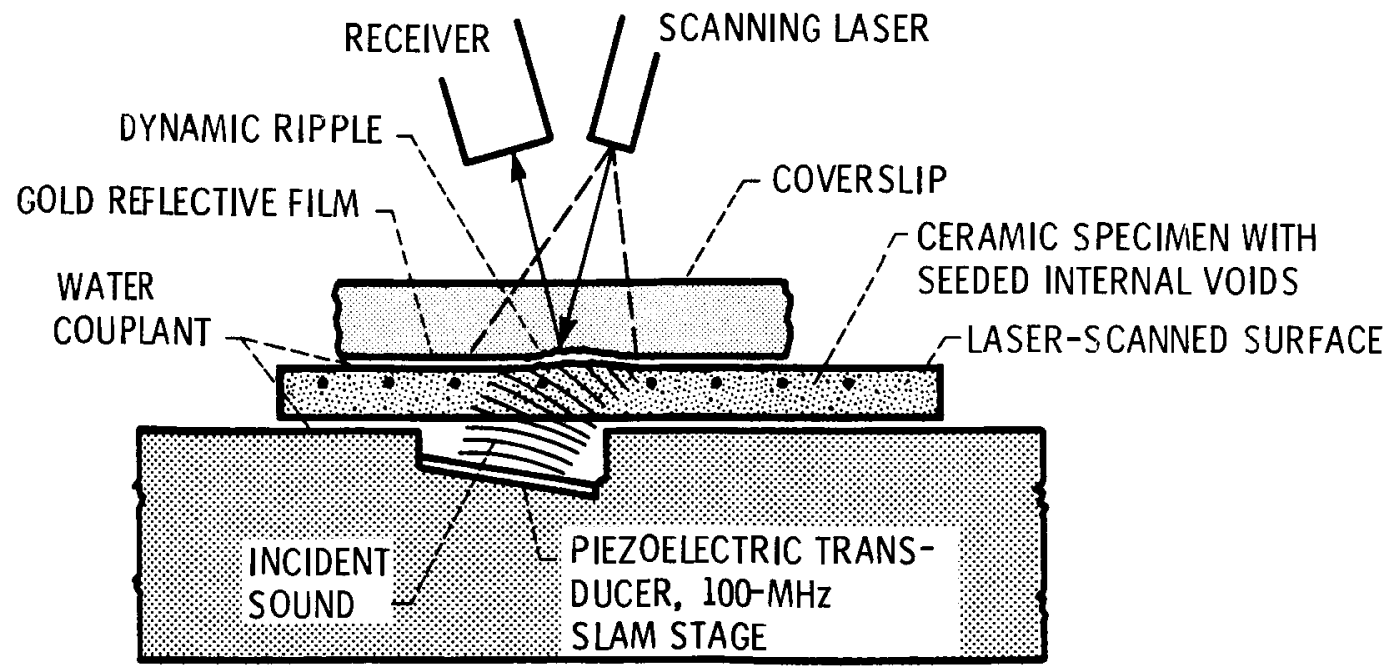

Figure 3. - Scanning laser acoustic microscopy (SLAM) of ceramic test bars containing seeded internal defects. 


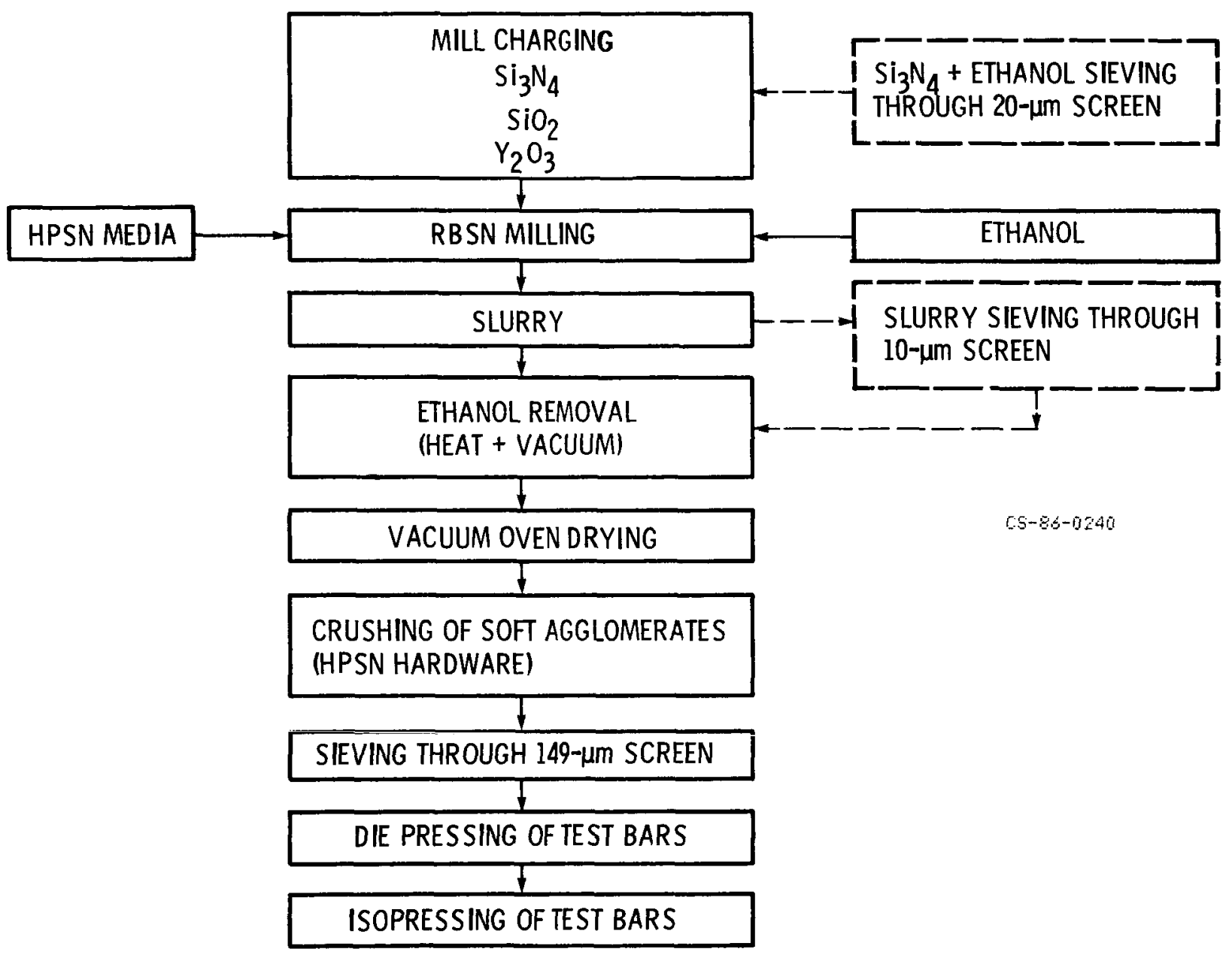

Figure 4. - Powder processing of $\mathrm{Si}_{3} \mathrm{~N}_{4}-\mathrm{SiO}_{2}-\mathrm{Y}_{2} \mathrm{O}_{3}$ composition NASA 6Y. 


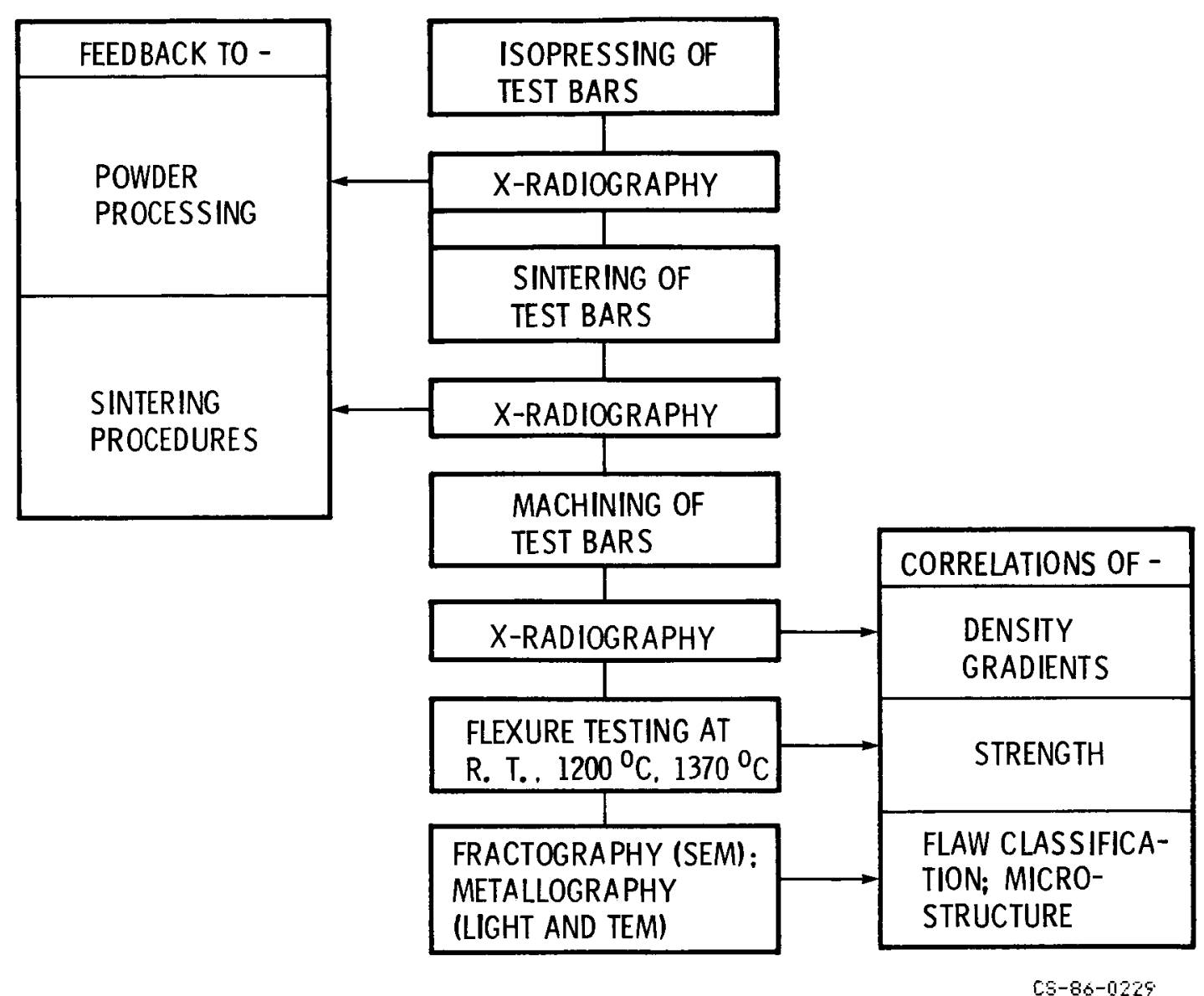

Figure 5. - Characterization, testing, and evaluation of NASA $6 \mathrm{Y} \mathrm{Si}_{3} \mathrm{~N}_{4}$. 


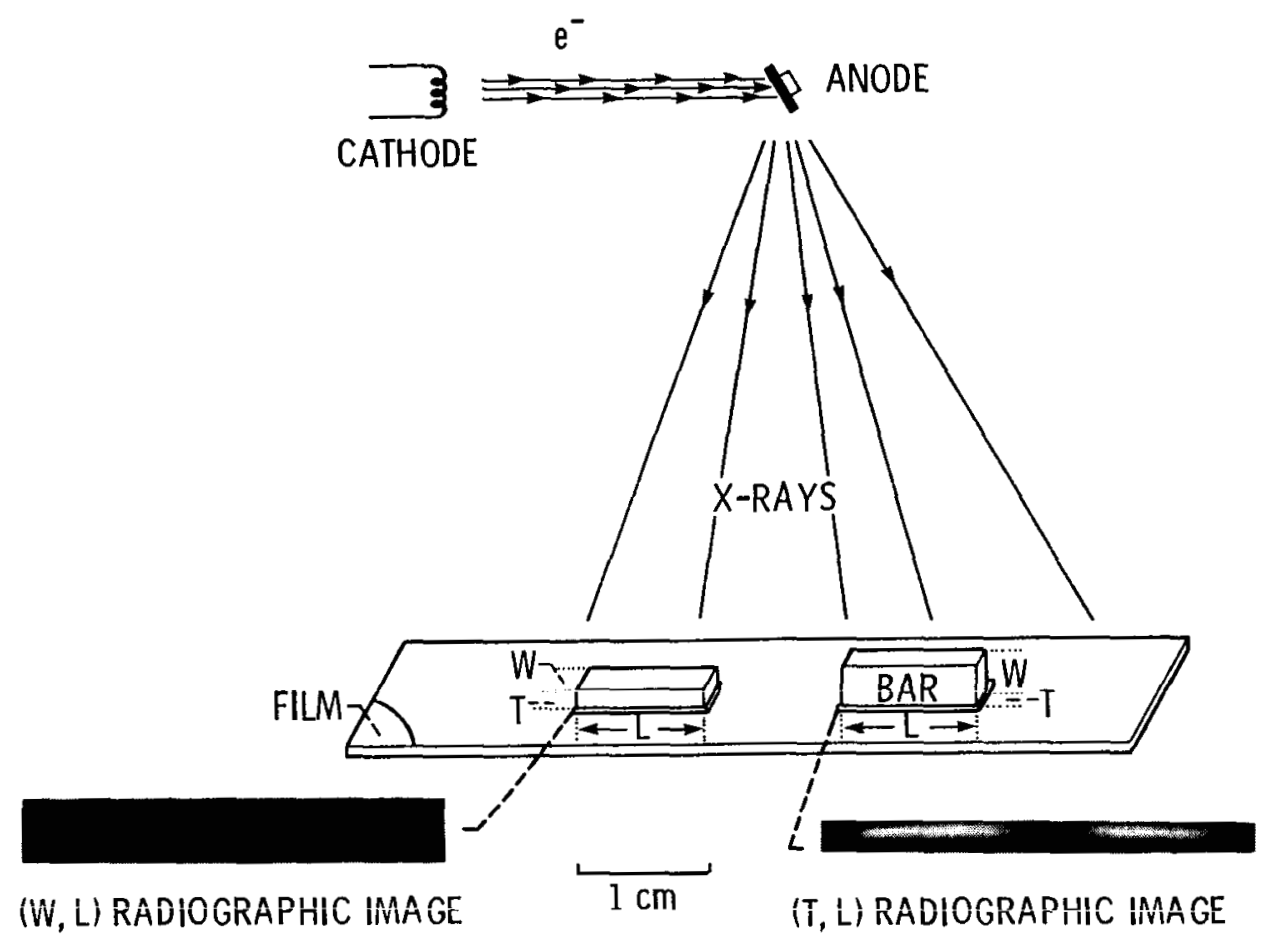

CS-85-4207

Figure 6. - Schematic configuration of conventional radiography employed for characterization of NASA $6 \mathrm{Y} \mathrm{Si}_{3} \mathrm{~N}_{4}$ test bars $\mathrm{L}=3.0 \mathrm{~cm} . \mathrm{W}=0.56 \mathrm{~cm}$, $T=0.28 \mathrm{~cm}$ ). 

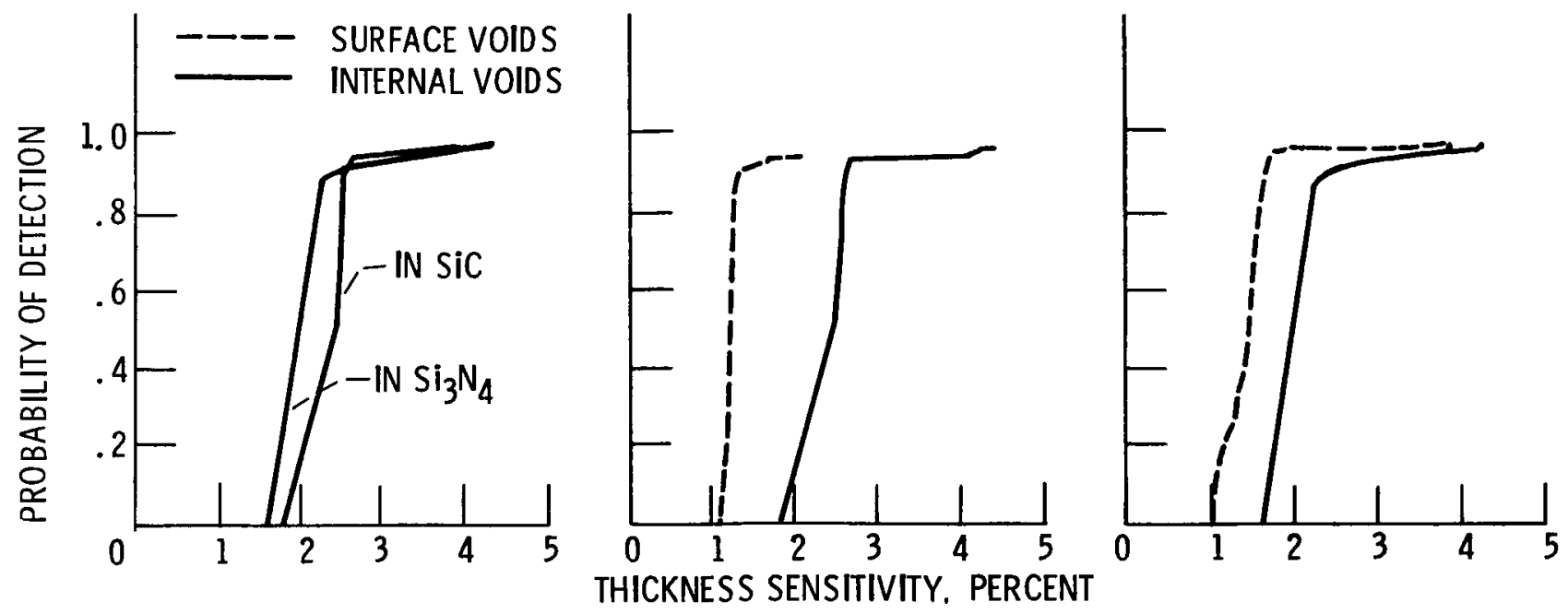

(a) Green $\mathrm{SiC}$ and $\mathrm{Si}_{3} \mathrm{~N}_{4}$

(b) Green SiC.

(c) Green $\mathrm{Si}_{3} \mathrm{~N}_{4}$.

Figure 7. - Lower bound probability of detecting surface and internal voids in green isopressed SiC and $\mathrm{Si}_{3} \mathrm{~N}_{4}$ bars by microfocus $\mathrm{x}$-ray. Thickness sensitivity in percent equals 100 tvoid dimension in $x$-ray beam direction)/(thickness of specimen in same direction). Probability of detection calculated at 0.95 confidence level.

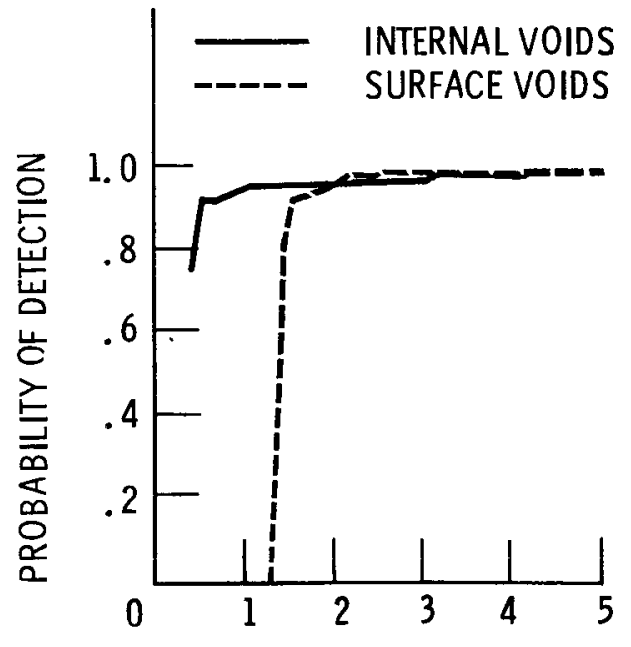

(a) Sintered $\mathrm{Si}_{3} \mathrm{~N}_{4}$.

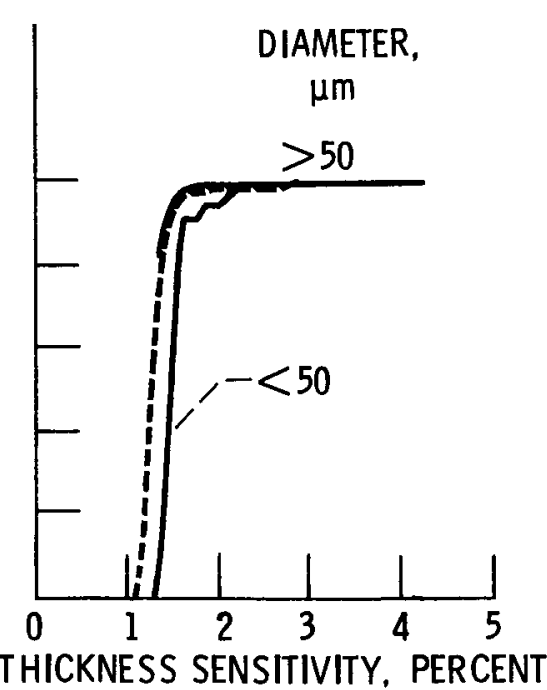

(b) Sintered SiC.

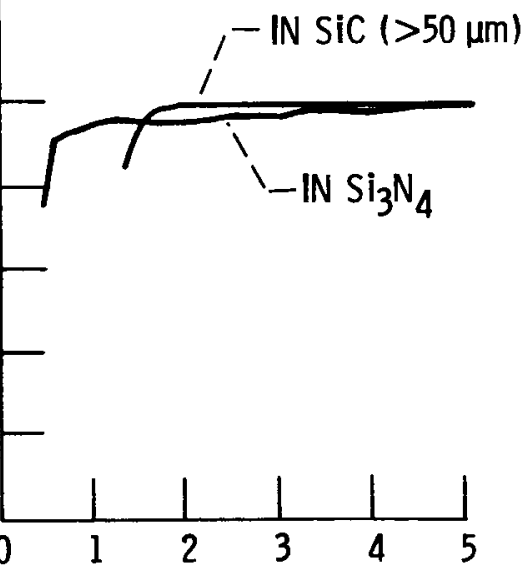

(c) Sintered $\mathrm{SiC}$ and $\mathrm{Si}_{3} \mathrm{~N}_{4}$.

Figure 8. - Lower bound probability of detecting surface and internal voids in sintered $\mathrm{SiC}$ and $\mathrm{Si}_{3} \mathrm{~N}_{4}$ bars by microfocus $x$-ray. Thickness sensitivity in percent equals 100 (void dimension in $x$-ray beam direction)/(thickness of specimen in same direction). Probability of detection calculated at 0.95 confidence level. 


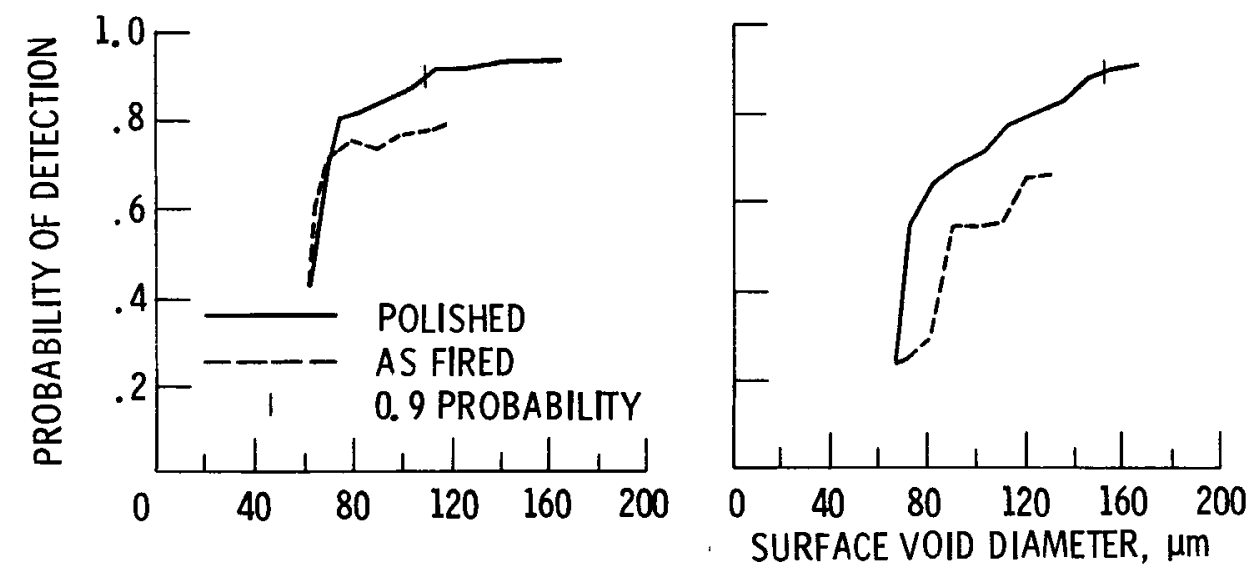

(a) Specimen thickness, $2 \mathrm{~mm}$.

(b) Specimen thickness, $3 \mathrm{~mm}$.

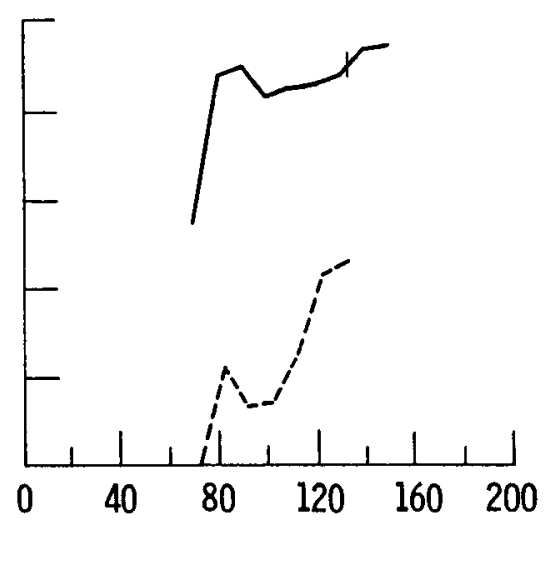

(c) Specimen thickness, $4 \mathrm{~mm}$.

Figure 9. - Effect of specimen thickness and surface condition on probability of detecting voids in sintered silicon nitride by SLAM. Effect of thickness is evident only for specimens with as-fired surfaces. Probability of detection calculated at 0.95 confidence level. 


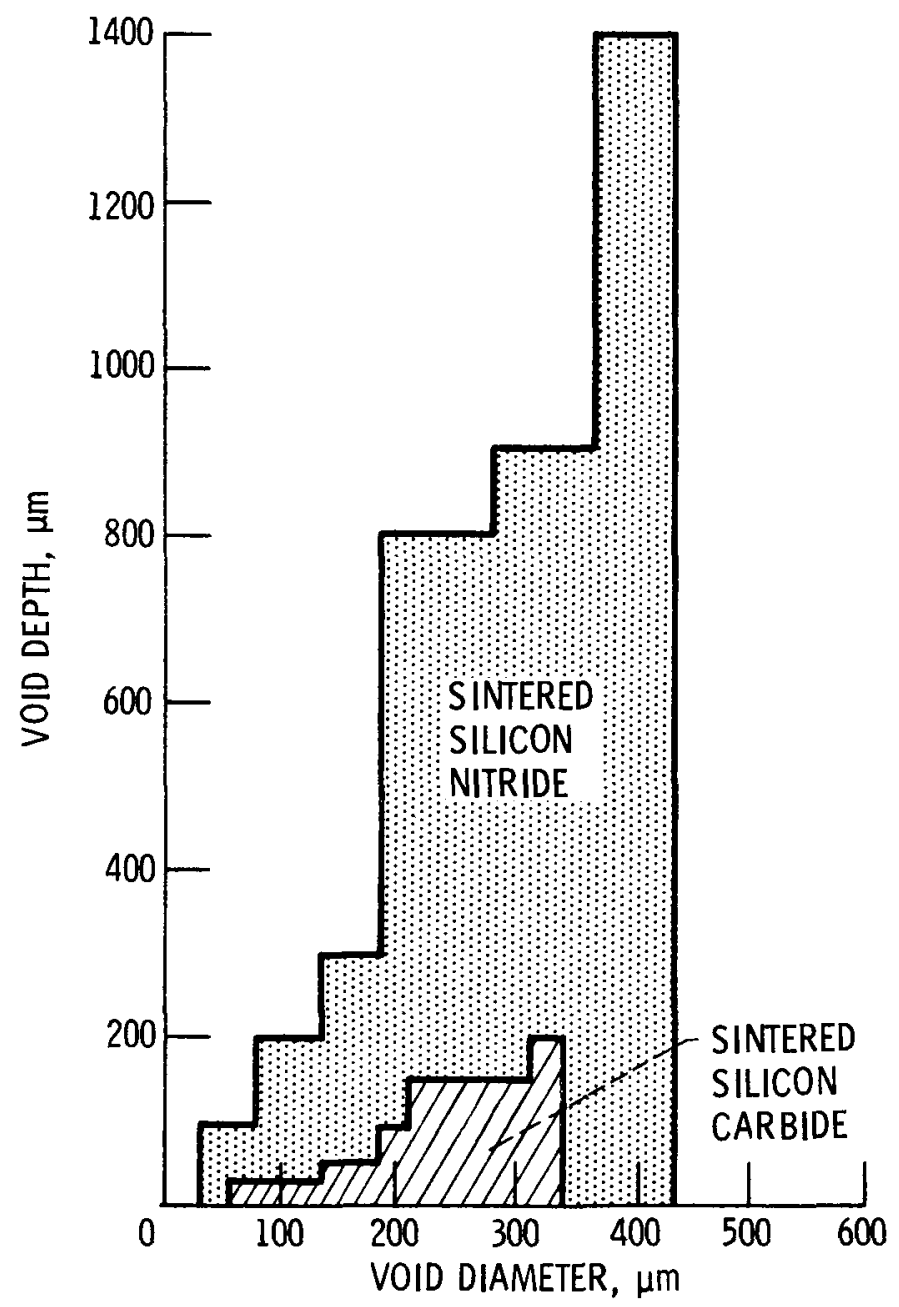

Figure 10. - Effect of void diameter, void depth, and matrix material on probability of detecting internal voids by scanning laser acoustic microscopy. Probability of detection. 0.9 at 0.95 confidence limit. 


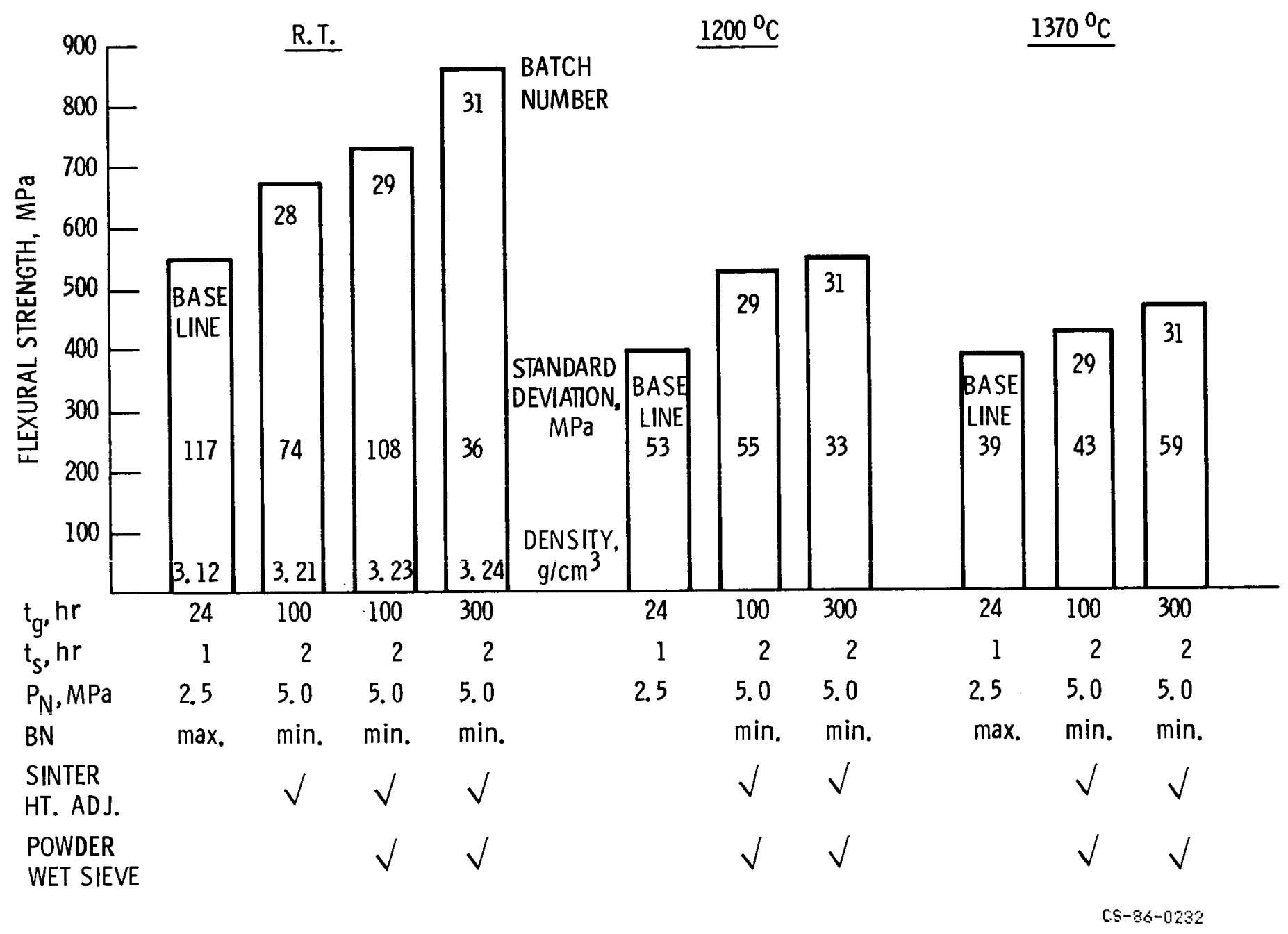

Figure 11. - Effect of modified processing/sintering procedures on flexural strength of NASA $6 \mathrm{Y} \mathrm{Si}_{3} \mathrm{~N}_{4}$ sintered at $2140^{\circ} \mathrm{C}$. 


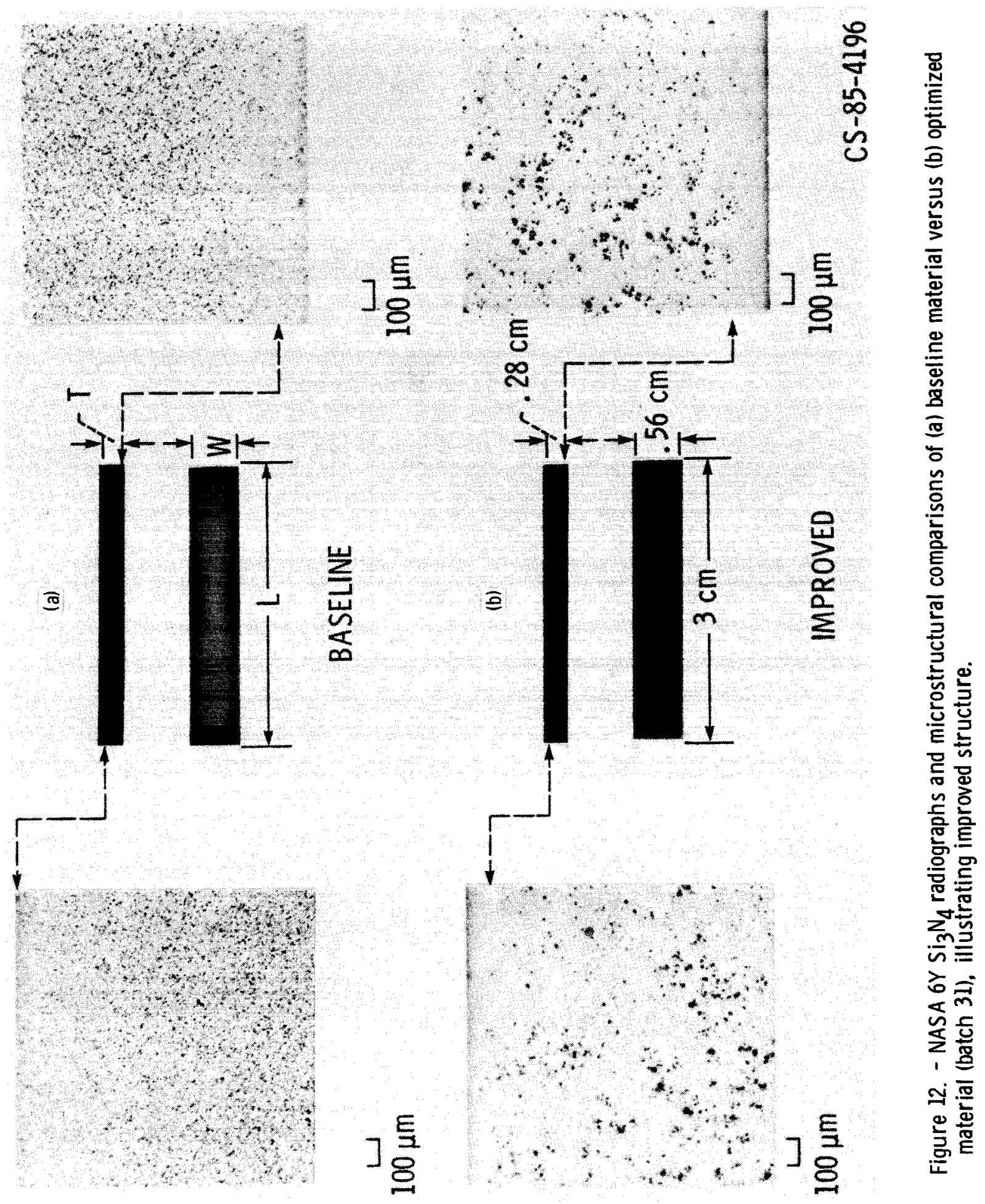




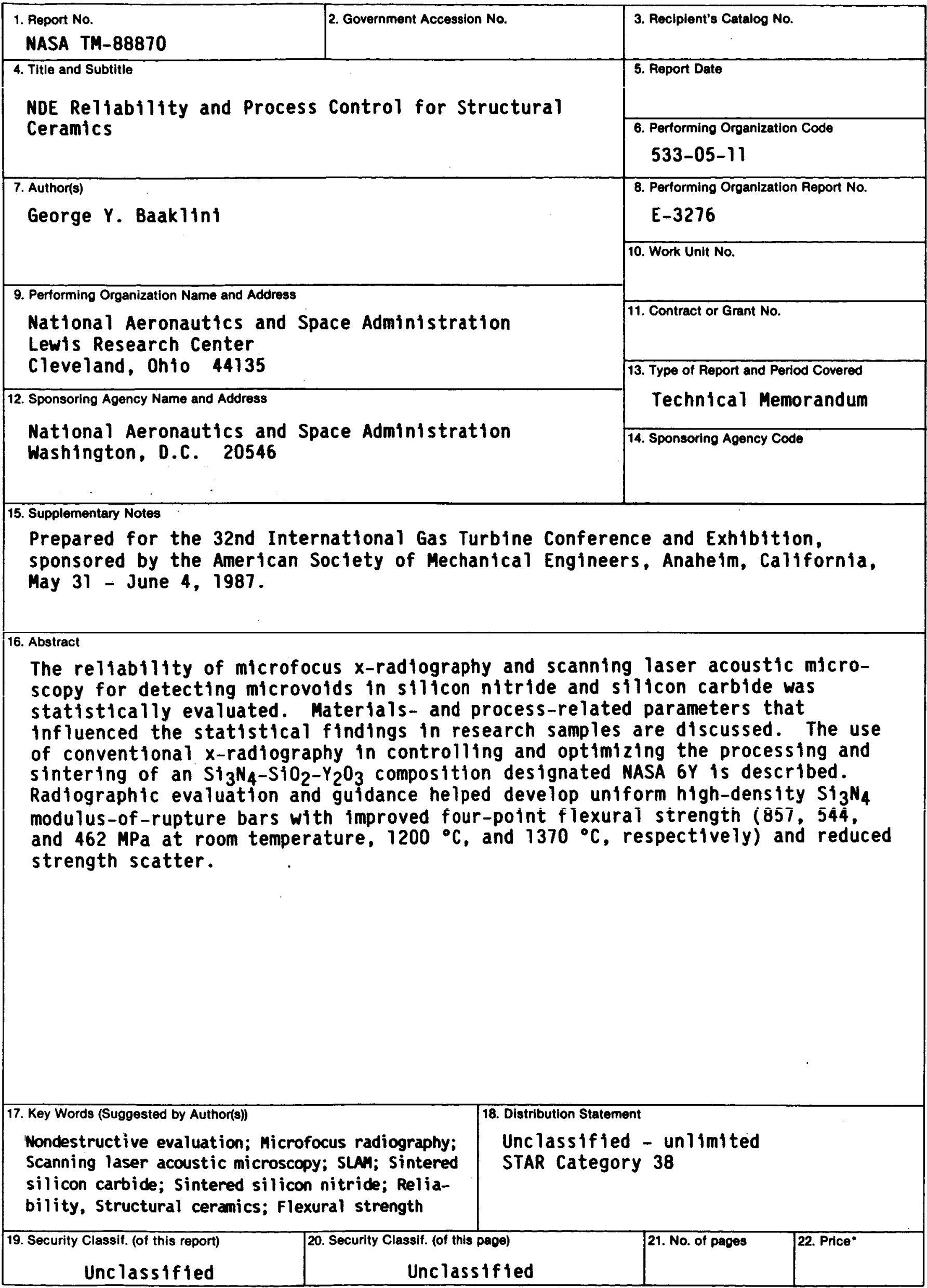

*For sale by the National Technical Information Service, Springfield, Virginia 22161 